\title{
Combined use of exhaled nitric oxide and airway hyperresponsiveness in characterizing asthma in a large population survey
}

\author{
A.H. Henriksen*, T. Lingaas-Holmen**, M. Sue-Chu*, L. Bjermer*
}

Combined use of exhaled nitric oxide and airway hyperresponsiveness in characterizing asthma in a large population survey. A.H. Henriksen, T. Lingaas-Holmen, M. Sue-Chu, L. Bjermer. (C)ERS Journals Ltd 2000.

ABSTRACT: The aim of the present study was to see whether measurements of airway hyperresponsiveness (AHR) and nitric oxide (NO) in exhaled air (ENO) either separately or in combination, could differentiate between asthmatics and healthy control subjects in a population based survey.

In central Norway 8,571 adolescents participated in a large-scale epidemiological survey (Young Helseundersøkelsen i Nord-Trøndelag (Health Survey in NorthTrøndelag; HUNT). Asthmatic symptoms when exposed to pollen, pets or house-dust were reported by $7.8 \%$ (suspected asthmatics), while $56 \%$ reported no asthmatic or allergic symptoms (control subjects). From these respective groups 151 and 213 adolescents were investigated with allergy screening, measurements of exhaled and nasal NO, and methacholine challenge test.

AHR (provocative dose of methacholine causing a $20 \%$ fall in forced expiratory volume in one second (PD20) $<2 \mathrm{mg}$ ) was confirmed in $\mathbf{7 5 \%}$ of the suspected asthmatics versus $25 \%$ of the control subjects, whereas $52 \%$ versus $20 \%$ had elevated levels of ENO ( $\geq 8$ parts per billion (ppb)). ENO and dose response ratio to methacholine (DRR) were positively correlated $(r=0.41, p<0.001)$. ENO was significantly elevated in atopic versus nonatopic suspected asthmatics (11.7 ppb and $5.6 \mathrm{ppb}$ respectively, $p<0.001)$. Suspected asthmatics with both AHR and atopy had the highest levels of ENO (14.2 ppb).

It is concluded that measurements of nitric oxide in exhaled air alone are not a useful tool in diagnosing asthma in population surveys, but that the combination of airway hyperresponsiveness and elevated nitric oxide in exhaled air is a very specific finding for allergic asthma. The use of dose response ratio to methacholine did not provide any additional information to the provocative dose of methacholine causing a $\mathbf{2 0} \%$ fall in forced expiratory volume in one second in this study.

Eur Respir J 2000; 15: 849-855.

Asthma is caused by inflammation in the lower airways. In population studies asthma is defined as the presence of specific respiratory symptoms alone or as symptoms combined with unspecific airway hyperresponsiveness (AHR). Traditionally, AHR is defined as a certain fall in forced expiratory volume in one second (FEV1) after bronchial challenge with e.g. methacholine or histamine. AHR is being used as an indirect marker of the degree of airway inflammation. However, recent data suggest that AHR merely reflects the presence of remodelling of the airway wall. Hoshino et al. [1] found that the thickness of the subepithelial layer was inversely correlated to the minimum dose of methacholine as the indicator of bronchial sensitivity, while the duration of the disease, diurnal peak expiratory flow (PEF) and FEV1 were not related to the thickness of the subepithelial layer. Results from studies on the association between inflammatory cells in induced sputum and AHR are rather conflicting [2,3]. Thus, it may be concluded that AHR is related to various pathophysiological factors, inflammation being only one of them.
*Dept of Lung Medicine, Norwegian University of Science and Technology, Trondheim, Norway. **National Institute of Public Health, Community Medicine Research Unit, Verdal, Norway.

Correspondence: L. Bjermer, Dept of Lung Medicine, Norwegian University of Science and Technology, N-7006 Trondheim, Norway. Fax: 4773867424

\section{Keywords: Adolescents}

airway hyperresponsiveness

allergic asthma

atopy

exhaled nitric oxide

provocative dose of methacholine causing a $20 \%$ fall in forced expiratory volume in one second

Received: June 231999

Accepted after revision January 32000

A.H. Henriksen is funded by a research grant from The Norwegian Research Council. This study was sponsored by The Norwegian Asthma and Allergy Association and by AstraZeneca (S. Karger, Norway).
While some prefer to define AHR as a $20 \%$ fall in FEV1 after the delivery of a cumulative dose of a provocative substance (PD20) [4], others have proposed the degree of response to a certain dose i.e. dose response ratio (DRR) as a better tool to select those with clinically relevant AHR $[5,6]$. One aim of the present study was to evaluate in the epidemiological setting a new tidal volume triggered system for methacholine challenge, Automatic Provocation System (APS, Erich Jaeger, Höchberg, Germany). The authors wanted to see how measurements of AHR, both defined as PD20 and DRR, could differ between asthmatics and healthy control subjects in a population based survey.

An alternative noninvasive measurement of lower airway inflammation is the level of nitric oxide in orally exhaled air (ENO). Asthmatics have increased levels of ENO [7], and in a recent study of asthmatic children, a decrease in ENO after a period of treatment with inhaled steroids was demonstrated [8]. In several studies a significant positive correlation between eosinophils in induced 
sputum and ENO has been demonstrated [3]. In the population study by SALOME et al. [9] of young adults aged 2325 yrs with and without wheeze or AHR, levels of ENO were found to be log-normally distributed in a population sample and a highly repeatable measurement. How an elevated value of ENO should be interpreted in clinical practice or in epidemiological studies is still not clear. Combined use of AHR and ENO, as screening tools has not previously been reported. Thus, a second aim of the present study was to find how ENO, either alone or in combination with AHR, could differentiate between health and disease in a population study, when adolescents with a history of allergy and wheeze were compared to adolescents without allergic or respiratory symptoms.

\section{Materials and methods}

\section{Subjects}

All inhabitants $\geq 13$ yrs $(105,000)$ in the County of North-Trøndelag in central Norway were invited to join a health survey (Helseundersøkelsen i Nord-Trøndelag (Health Survey in North-Trøndelag; HUNT)) conducted by the Norwegian State Institute of Public Health. As part of this, 8,571 adolescents aged 13-19 yrs were investigated with a self-administered questionnaire, a structured interview conducted by specially trained nurses, and a clinical investigation with flow volume spirometry (Young-HUNT). The interview was based on International Study of Asthma and Allergies in Childhood (ISAAC) [10], and dealt with allergy related symptoms from the upper and lower airways, respiratory symptoms, diagnosed asthma and use of asthma medication. The response rate was $90 \%$.

According to their answers during the interview, the current authors defined four symptom groups: 1) hay fever without lower respiratory symptoms, (hay fever; 929 subjects, $10.8 \%)$; 2) one or more episodes of wheeze during the last 12 months when exposed to pollen, pets, or house-dust, (subjects with suspected allergic asthma; 665 subjects, $7.8 \%$ ); 3 ) one or more episodes of wheeze during the last 12 months not related to exposure to pollen, pets, or house-dust, (subjects with suspected nonallergic asthma; 1,577 subjects, $18.4 \%$ ); and 4) no history of wheeze, allergy or hay fever, (healthy control subjects; 4,802 subjects, 56\%). Adolescents from each symptom group were randomly invited to participate in a phase II study (young-HUNTasthma-allergy) for allergy screening, measurements of exhaled and nasal nitric oxide (NO) and a methacholine bronchoprovocation test. They also answered a questionnaire that repeated questions from the interview in the phase I study. The investigations took place in five different localities all over the county. A total number of 722 adolescents were investigated, among them 100 subjects with hay fever, 151 subjects with suspected allergic asthma, 258 subjects with suspected nonallergic asthma, and 213 healthy control subjects. Results from the second group (subjects with suspected allergic asthma) and the fourth group (healthy control subjects) are discussed in this article, referred to as suspected asthmatics and control subjects respectively. Data from the group with hay fever have been reported previously [11].

The suspected asthmatics were investigated during the non-pollen seasons of 1997 and 1998 and the controls were investigated in the period from September 1997 to June 1998. They were from both rural and suburban areas with mainly a coastal climate.

Those who were taking antiasthmatic drugs were asked not to take inhaled or oral $\beta_{2}$-agonists $12 \mathrm{~h}$ before the investigation and smokers were asked to refrain from smoking 30 min before their appointments. A nurse and a physician carried out the investigations. Those with symptoms of lower respiratory tract infection or sinusitis were not investigated, but tested on a later occasion if possible.

The subjects were not paid for attending the study, and all subjects, as well as the parents of those subjects $<16$ yrs of age, gave written informed consent prior to participation. The study was approved by the regional ethical committee in Trondheim.

Table 1. - Subject characteristics in adolescents with a history of asthmatic symptoms when exposed to allergens, suspected asthmatics (138 subjects), and adolescents with no history of wheeze or allergy, control subjects (193 subjects)

\begin{tabular}{|c|c|c|c|c|c|c|}
\hline & \multicolumn{3}{|c|}{ Suspected asthmatics } & \multicolumn{3}{|c|}{ Control subjects } \\
\hline & Female & Male & Total & Female & Male & Total \\
\hline Included & $77(56)$ & $61(44)$ & 138 & $104(54)$ & $89(46)$ & 193 \\
\hline Age yrs & $16.8^{+}$ & $16.8^{+}$ & $16.8^{+}$ & 16.1 & 16.0 & 16.0 \\
\hline Smokers \% & $22(29)^{*,+}$ & $7(12)$ & $29(21)$ & $11(11)$ & $14(16)$ & $25(13)$ \\
\hline BMI mean $\mathrm{kg} \cdot \mathrm{m}^{-2}$ & $23.6^{+}$ & $23.2^{+}$ & 23.4 & 22.1 & 21.7 & 21.9 \\
\hline $95 \% \mathrm{CI}$ & $22.7-24.5$ & $22.2-24.1$ & $22.8-24.1$ & $21.5-22.8$ & $21.1-22.3$ & $21.5-22.4$ \\
\hline FEV1 \% & 106 & 103 & 105 & $113^{++}$ & $110^{+}$ & $111^{++}$ \\
\hline $95 \%$ CI & $102-109$ & $100-106$ & $102-107$ & $111-115$ & $107-112$ & $110-113$ \\
\hline FVC basal \% & 105 & 107 & 106 & 108 & 105 & 107 \\
\hline $95 \%$ CI & $102-108$ & $103-110$ & $104-108$ & $105-110$ & $103-108$ & $105-108$ \\
\hline MMEF basal \% & 90 & 86 & 88 & $103^{++}$ & $102^{++}$ & $103^{++}$ \\
\hline $95 \%$ CI & $84-96$ & 79-93 & $84-93$ & 99-108 & $97-106$ & 99-106 \\
\hline FEV1/FVC ratio & $86^{* *}$ & 80 & 83 & $89^{*,++}$ & $86^{++}$ & $88^{++}$ \\
\hline $95 \% \mathrm{CI}$ & $84-88$ & $78-82$ & $82-85$ & $88-90$ & $85-88$ & 87-89 \\
\hline
\end{tabular}

Data are presented as absolute numbers with the percentage in parenthesis, unless indicated otherwise. $*$ : $\mathrm{p} \leq 0.05 ; * *$ : $\mathrm{p}<0.001$, marks sex differences within the groups. ${ }^{+}: \mathrm{p} \leq 0.05 ;^{++}: \mathrm{p} \leq 0.001$, marks differences between the two groups (female versus female, male versus male, or total versus total). BMI: body mass index; 95\% CI: 95\% confidence interval; FEV1\%: Basal value of FEV1 as per cent of predicted value; FVC basal \%: basal value of forced vital capacity as per cent of predicted value; MMEF: basal value of maximal mid-expiratory flow as per cent of predicted value. 


\section{Methods}

Allergy screening. An in vitro test (Phadiatop $\mathrm{CAP}^{\mathrm{TM}}$; Pharmacia Diagnostics, Lund, Sweden) was used to analyse serum for the presence of immunoglobulin (Ig)E. All samples with a positive Phadiatop were analysed for the level of specific IgE (RAST; Pharmacia Diagnostics) against house dust mite (Dermatophagoides pteronyssinus), mould, mugwort, timothy grass and birch pollen, and dander from cat, dog and horse. Specific IgE concentrations were recorded in a scale $0-5$, and a test result $\geq 2$ was regarded as positive.

Measurements of exhaled and nasal nitric oxide. ENO and nasal NO measurements were performed in accordance with the European Respiratory Society (ERS) Task Force [12] with an LR 2000 NO gas analyser (Logan Research Ltd, London, UK) and defined in parts per billion (ppb). The subjects were in a seated position and for each subject two acceptable curves with a plateau phase of ENO and nasal NO were saved. For measurements of ENO the subjects exhaled from total lung capacity to residual volume. In order to close the soft palate, they breathed against a 5- $\mathrm{cmH}_{2} \mathrm{O}$ resistance. The exhalation was controlled with a biofeedback monitor, and the subjects were asked to aim at an exhalation flow rate of $250 \mathrm{~mL} \cdot \mathrm{s}^{-1}$. The sampling flow rate was $250 \mathrm{~mL} \cdot \mathrm{min}^{-1}$ for both measurements of ENO and nasal NO. Nasal measurements were taken during a breathhold for at least $15 \mathrm{~s}$ after a forced inspiration through the nose. All tests of $\mathrm{NO}$ were taken prior to the bronchial challenge test.

Flow-volume spirometry. A MasterScope spirometer, software version 4.1 (Erich Jaeger). Reference values from the study by ZAPLETAL et al. [13] for subjects $\leq 18$ yrs and The European Coal and Steel Community (ECSC) for subjects $>18$ yrs were used [14].

Bronchial provocation tests. These were carried out with a tidal volume triggered equipment, Automatic Provocation System (APS; Erich Jaeger), that delivered a cumulative dose of 2,000 $\mu \mathrm{g}$ methacholine in five increments. Subjects with a fall in FEV1 of $\geq 20 \%$ were defined as having confirmed AHR. DRR to methacholine was calculated as the maximal fall in FEV1 divided by the total dose of methacholine given during the bronchoprovocation test. If prechallenge FEV1 was $<80 \%$ of predicted, a reversibility test was performed in which the subject inhaled $0.5 \mathrm{mg}$ terbutalin, and after 10 min a new flow-volume-spirometry was carried out. The test was regarded as positive if there was an increase in prechallenge FEV 1 of at least $15 \%$ of baseline value. From the two groups, $25 \%$ of the adolescents had symptoms of an ongoing light upper respiratory tract infection (ongoing cold). To analyse the influence of a cold on bronchial hyperresponsiveness and ENO, 22 subjects with an ongoing cold and AHR were invited to a second identical investigation 4-8 weeks after the first visit.

\section{Statistical analyses}

Data from measurements of DRR and ENO and nasal NO were close to log-normal distributed, thus parametric tests were used in log values and results presented as geometric mean. Unpaired data and follow-up data from subjects with an ongoing cold were analysed with independent-samples t-tests and paired-samples t-tests respectively. When comparing age groups one-way analysis of variance (ANOVA) tests were applied. Categorical variables were compared with Chi-squared tests. When checking possible confounders, categorical and continuous variables were analysed with logistic and linear regression respectively. Pearson's correlation coefficient was calculated for correlations between variables. Relative risk was estimated to measure the strength between the presence of various factors and the occurrence of elevated levels of ENO. A p-value of $<0.05$ was regarded as statistically significant.

\section{Results}

Of the 151 adolescents with suspected asthma, four were tested for reversibility instead of AHR because of reduced FEV1 (three subjects) or complications during a former challenge test (one subject). An increase in FEV1 of $\geq 15 \%$ from baseline was regarded as positive. As it can be expected that subjects with a positive reversibility test have airway hyperresponsiveness, these four subjects were classified as having confirmed AHR. From the two groups, suspected asthmatics and control subjects, acceptable curves of ENO and nasal NO and Phadiatop tests were achieved from 327 (99\%), 319 (96\%) and 322 (97\%) subjects respectively.

\section{Attendance rate}

In the group of suspected asthmatics, the first 67 adolescents were investigated at a research centre $10-50 \mathrm{~km}$ from their schools, and the attendance rate was low, 50.4\%. The other adolescents were investigated at their schools, and the attendance rate increased to $71 \%$ for the suspected asthmatics and $68 \%$ in the control group. There were no significant differences in FEV1 \% pred, DRR to methacholine or levels of ENO between the suspected asthmatics investigated at the research centre and those investigated at their schools.

\section{Subject characteristics}

The adolescents were 13-22 yrs of age. The suspected asthmatics were statistically older than the control subjects, mean age 16.8 yrs versus 16.0 yrs, $(\mathrm{p}<0.001$; table 1$)$. In the group of suspected asthmatics, both females and males had significantly higher body mass index (BMI) when compared with females and males in the control group. Significantly fewer of the suspected asthmatics exercised on a regular basis compared to the control subjects, $60 \%$ versus $77 \%$, $(\mathrm{p}=0.001)$. Among females with suspected asthma there were significantly more smokers both compared to males with suspected asthma $(p=0.02)$, and compared to females in the control group, $(\mathrm{p}=0.008$; after adjusting for age). 


\section{The influence of an ongoing cold}

Twenty-eight per cent of the control subjects versus $25 \%$ of the suspected asthmatics reported symptoms of an ongoing cold, mainly described as nasal discharge. From the phase II study, 22 subjects with AHR and an ongoing cold were retested at a follow-up visit after $4-8$ weeks. Of these 22 subjects, three were suspected asthmatics, 11 were control subjects, and eight subjects belonged to a third group with suspected nonallergic asthma. Compared to the findings during the initial visit, both DRR and ENO were significantly reduced at the follow-up visit from geometric mean 33.1 to $27.6 \% \cdot \mathrm{mg}^{-1}$ ( $\mathrm{p}<0.0001$ ), and from 6.0 to 5.7 $\mathrm{ppb}(\mathrm{p}=0.006)$ respectively. However, when adjusting for the presence of a cold when comparing different groups with respect to hyperresponsiveness or levels of ENO the results were not significantly altered.

\section{Incidence data}

The phase-II study was carried out 0.5-2.5 yrs after the phase-I study (mean 13.5 and 10 months in the suspected asthmatics and the control subjects, respectively). In the control group $20(9.4 \%)$ of the 213 adolescents reported $\geq 1$ episodes of wheeze during the last 12 months prior to the investigation. The yearly incidence of asymptomatic adolescents to acquire asthmatic symptoms was $11.3 \%$.

Fifty-five per cent of the subjects with acquired wheeze had a positive AHR ( $>20 \%$ fall in FEV1) compared to $25 \%$ of those who remained asymptomatic, $(\mathrm{p}<0.02)$. Moreover, there was a greater proportion of smokers in the group with acquired wheeze compared to the asymptomatic control subjects, $35 \%$ and $13 \%$ respectively, $(\mathrm{p}<0.02)$. The proportion with a positive allergy test was not significantly higher among the control subjects with acquired wheeze, and there were no differences in the levels of ENO or any sex differences compared to those who remained asymptomatic. The 20 subjects with acquired wheeze were excluded from the control group leaving 193 adolescents as control subjects. None of the control subjects used oral or inhaled $\beta_{2}$-agonists or steroids.

Of the 151 suspected asthmatics, 12 subjects had not experienced any episodes of wheeze or used any asthma medication during the 12 months preceding investigation. The yearly remission rate for subjects with suspected allergic asthma to become asymptomatic was $7.1 \%$. In this group the number of subjects with bronchial hyperresponsiveness and subjects with sensitization towards house dust mite were significantly lower compared to those with continuous wheeze, four (33\%) versus $100(75 \%), \mathrm{p}=0.02$ and one $(8 \%)$ versus $61(45 \%), \mathrm{p}=0.02$ respectively. Among the 12 subjects without recent wheeze, 11 were nonsmokers. These 12 subjects plus one that had not answered the questionnaire were excluded, leaving 138 adolescents in the group of suspected asthmatics. In this group $49(36 \%)$ and $14(10 \%)$ subjects had been taking inhaled or oral $\beta_{2^{-}}$ agonists respectively during the last week. Thirty-nine subjects $(28 \%)$ had been taking inhaled steroids during the last 6 months.

\section{Allergen sensitization}

One hundred subjects (74\%) with suspected asthma versus $43(23 \%)$ control subjects $(\mathrm{p}<0.001)$ had a positive Phadiatop test and were defined as being atopic. In the group of suspected asthmatics, sensitization towards timothy grass $(56 \%)$, house dust mite $(45 \%)$, and dog dander $(40 \%)$ were the most frequent, whereas sensitization towards house dust mite $(11 \%)$, timothy grass $(8.5 \%)$, and birch pollen (4.3\%) were most frequent among the control subjects. Among suspected asthmatics significantly more males than females had a positive Phadiatop test.

\section{Basal lung function and airway hyperresponsiveness}

Both FEV1, maximal mid-expiratory flow (MMEF25$75 \%$ ), and $\mathrm{FEV} 1 /$ forced vital capacity (FVC) ratio as per cent of predicted values were significantly lower in suspected asthmatics compared to control subjects $(p<0.001$; tables 1 and 2). The FEV1/FVC ratio was significantly elevated in females compared to males. However, this difference disappeared after adjusting for height.

A maximal cumulative dose of $2 \mathrm{mg}$ methacholine was delivered during the bronchial provocation test, and 25\% of the asymptomatic control subjects versus $75 \%$ of the suspected asthmatics had AHR defined as $\geq 20 \%$ fall in FEV1. Suspected asthmatics with confirmed AHR were defined as asthmatics. To further interpret how different cumulative doses of methacholine would influence the sensitivity and specificity of the test, three different cut-off points were analysed, $2 \mathrm{mg}, 1 \mathrm{mg}$, and $0.5 \mathrm{mg}$ (table 2). Corresponding cut-off points of the DRR to methacholine were also analysed. When the cut-off points of PD20 and DRR were decreased from $2 \mathrm{mg}$ to $0.5 \mathrm{mg}$ and increased from $10 \% \cdot \mathrm{mg}^{-1}$ to $40 \% \cdot \mathrm{mg}^{-1}$, respectively the sensitivity was reduced from $74 \%$ to $60 \%$ whereas the specificity was increased from $75 \%$ to $95 \%$ for both methods.

\section{Exhaled nitric oxide}

Levels of ENO were reduced in smokers versus nonsmokers, but the difference was significant only in the control group, geometric mean $4.4 \mathrm{ppb}$ in smokers versus $5.7 \mathrm{ppb}$ in nonsmokers, $(\mathrm{p}=0.02)$.

ENO was significantly elevated in suspected asthmatics compared to control subjects, $9.8 \mathrm{ppb}(95 \%$ confidence interval (CI) 8.5-11.3) versus $5.5 \mathrm{ppb}$ (95\% CI 5.1-5.9; $\mathrm{p}<0.001)$, and was further increased with the presence of AHR or atopy, (fig. 1). The highest mean NO level was found in suspected asthmatics with both confirmed AHR

Table 2. - Three different cut-off values for provocative dose of methacholine causing a $20 \%$ fall in forced expiratory volume in one second (PD20) in 134 suspected asthmatics and 193 control subjects

\begin{tabular}{lcc}
\hline PD20* & Suspected asthmatics & Control subjects \\
\hline $2 \mathrm{mg}$ & 74 & 25 \\
$1 \mathrm{mg}$ & 67 & 16 \\
$0.5 \mathrm{mg}$ & 60 & 5 \\
\hline
\end{tabular}

Data are presented as percentages. *: PD20 given as a cumulative dose of methacholine. 

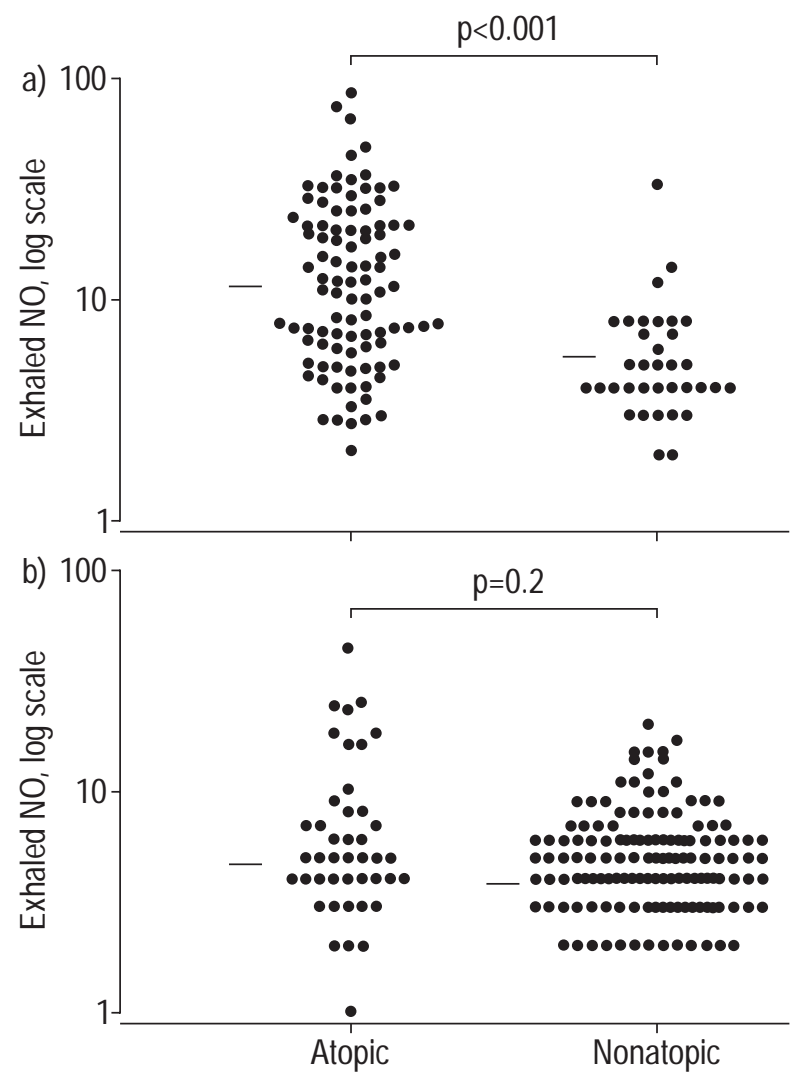

Fig. 1. - Exhaled nitric oxide in atopic versus nonatopic subjects. a) 131 suspected asthmatics and b) 187 control subjects. Geometric mean: atopic asthmatics, 11.7 parts per billion (ppb); nonatopic asthmatics, 5.6 ppb; atopic control subjects, $6.4 \mathrm{ppb}$; nonatopic control subjects, 5.3 ppb. Data are presented as individual values with geometric mean.

and atopy. This elevation was also significant when compared to control subjects with both AHR and atopy, 14.2 (95\% CI 12-17) versus 6.8 (95\% CI 5-10; p<0.005). There was no difference in ENO between nonatopic suspected asthmatics and nonatopic control subjects. However, of the nonatopic suspected asthmatics $71 \%$ had confirmed AHR versus $22 \%$ of the nonatopic control subjects, $(\mathrm{p}<0.001)$.

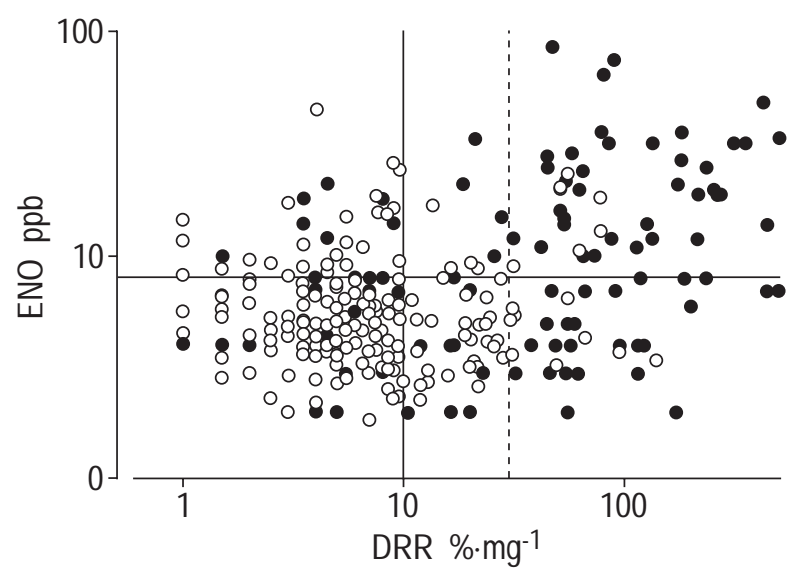

Fig. 2. - Correlation between exhaled nitric oxide (ENO) and dose response ratio (DRR) in suspected asthmatics (134) and control subjects (193). Horizontal line: $\mathrm{ENO}=8$ parts per billion (ppb); vertical line: $\mathrm{DRR}=10 \% \cdot \mathrm{mg}^{-1}$; vertical dashed line: $\mathrm{DRR}=30 \% \cdot \mathrm{mg}^{-1}$. $\mathrm{r}=0.41, \mathrm{p}<$ 0.001. $\bigcirc$ : control subjects; 1 : suspected asthmatics.
Table 3. - Relative risk of having an elevated level of exhaled nitric oxide ( $\geq 8$ parts per billion) in suspected asthmatics, relation to airway hyperresponsiveness (AHR) and atopy

\begin{tabular}{lcc}
\hline Groups & $\begin{array}{c}\text { Relative } \\
\text { risk }\end{array}$ & $95 \%$ CI \\
\hline $\begin{array}{l}\text { Suspected asthmatics versus control } \\
\text { subjects }\end{array}$ & $4.3^{* *}$ & $2.7-7.1$ \\
$\begin{array}{l}\text { Suspected asthmatics with versus } \\
\text { without AHR }\end{array}$ & $3.2^{*}$ & $1.4-7.2$ \\
$\begin{array}{l}\text { Suspected asthmatics with atopy } \\
\text { versus nonatopy }\end{array}$ & $4.2^{* *}$ & $1.8-10.0$ \\
$\begin{array}{l}\text { Confirmed asthma } \\
\text { nonatopy }\end{array}$ & $7.5^{* *}$ & $2.6-21.5$ \\
\hline
\end{tabular}

95\% CI: $95 \%$ confidence interval. ${ }^{\#}$ : Confirmed asthma is suspected asthmatics with confirmed AHR. Pearson Chi-Squared, $*$ : $<<0.01 ; * *: \mathrm{p}<0.001$.

Elevated levels of exhaled nitric oxide, relation to airway hyperresponsiveness and atopy

Of the suspected asthmatics $52 \%$ versus $20 \%$ of the control subjects had ENO equal to or above $8 \mathrm{ppb}$. The corresponding values for ENO $\geq 10 \mathrm{ppb}$ were $45 \%$ and $11 \%$, respectively (fig. 2 ). The relative risk of having an elevated level of ENO ( $\geq 8 \mathrm{ppb}$ ) was increased in suspected asthmatics compared to control subjects and was highest when atopic asthmatics (suspected asthmatics with confirmed AHR) were compared to nonatopic asthmatics (table 3).

Subjects with AHR and ENO $\geq 8$ ppb had significantly elevated DRR compared to those with confirmed AHR and lower levels of ENO, $108 \% \cdot \mathrm{mg}^{-1}(95 \%$ CI 81-144) versus $38 \% \cdot \mathrm{mg}^{-1}(95 \%$ CI $30-50), \mathrm{p}<0.001$, (fig. 2). ENO, but not DRR was significantly lower in atopic asthmatics who were taking inhaled glucocorticosteroids (IGCS) versus those who were not taking IGCS, geometric mean 11.8 versus $20.4 \mathrm{ppb}(\mathrm{p}=0.008)$ and 147 versus $147 \% \cdot \mathrm{mg}^{-1}$ $(\mathrm{p}=0.99)$ respectively. In the control group six males and four females had confirmed AHR plus ENO $\geq 8 \mathrm{ppb}$ (fig. 2 ). Compared to the rest of the control subjects, $50 \%$ versus $23 \%$ were atopic, $p=0.03$. Of the five nonatopic subjects, three were either smokers or had symptoms of an ongoing cold. There were no significant differences in basal lung function between these 10 subjects and the rest of the control subjects.

\section{Discussion}

This was primarily a cross-sectional study. However, for all subjects there was a follow-up period of 0.5-2.5 yrs prior to the investigation. During this period, the authors observed that 20 of the control subjects became symptomatic giving an annual incidence of acquiring asthma symptoms of $11 \%$. During the same period 12 of the suspected asthmatics became asymptomatic giving an annual remission rate of $7 \%$. From these follow-up data the authors found an association between presence and absence of AHR and the risk of developing asthma symptoms or to become asymptomatic respectively. Thus the follow-up period seems to also be advantageous for the cross-sectional study, providing a more correct discrimination between the groups. 
In the Young-HUNT study $5.6 \%$ of the females and $7 \%$ of the males were characterized as having suspected allergic asthma, giving an overall prevalence of $7.8 \%$ for both sexes. Most of the cases were mild intermittent or mild persistent with only $36 \%$ using $\beta_{2}$-agonists and $28 \%$ using inhaled corticosteroids on a regular basis. Despite this, on clinical examination, this group had significantly lower FEV1, MMEF25-75\% and FEV1/FVC ratio compared to their age matched controls. Moreover, $75 \%$ of the suspected asthmatics had a positive methacholine challenge test (confirmed AHR) and 74\% were atopic compared to $25 \%$ and $23 \%$, respectively, in the control group. Suspected asthmatics with confirmed AHR were defined as asthmatics.

Those with suspected asthma had higher BMI compared to the control subjects, while there was no difference in height between the groups. Others have reported a correlation between higher BMI and asthma symptoms [15]. Significantly fewer of the adolescents with suspected asthma exercised on a regular basis compared to the control subjects. KAPLAN and MONTANA [16] studied nonasthmatic obese children and found significantly greater exercise-induced fall in FEV1 and forced mid-expiratory flow (FEF25-75\%) in the obese children compared to control subjects. They asked whether exercise-induced bronchospasm leads to exercise avoidance and obesity or whether obesity causes or enhances bronchial hyperreactivity to exercise. It is beyond the scope of this article to answer these questions. However, as many as $60 \%$ of the adolescents with very mild to severe asthma did exercise on a regular basis, and it can be speculated that the level of physical activity in asthmatics is merely a matter of disease severity and control.

At the first visit $28 \%$ of the control subjects and $25 \%$ of the suspected allergic asthmatics had an ongoing cold. From the follow-up investigation of 22 subjects it may be concluded that the light upper airway infection to some degree influences both the level of ENO and the degree of AHR. However, when the authors adjusted for the presence of an ongoing cold in comparing AHR and levels of ENO among various groups, it did not have any significant impact on the results. Therefore the authors concluded that the influence of an ongoing cold was minor, and they decided to include these subjects in the further analysis.

In this study the authors used a new tidal volume triggered inhalation provocation system (APS; Erich Jaeger $\mathrm{Gmbh}$ ). A cut off dose of $2,000 \mu \mathrm{g}$ of methacholine was used to differentiate between presence and absence of AHR. Taking into account that there were many mild asthmatics among the suspected asthmatics investigated, all of these subjects could not be expected to have AHR. However, $2,000 \mu \mathrm{g}$ is probably a somewhat high dose level, though $25 \%$ of the control subjects were also positive. The dose giving the optimal specificity of $95 \%$, was $500 \mu \mathrm{g}$ with a somewhat lower, but probably acceptable sensitivity of $60 \%$. The use of DRR did not provide any additional information in this study. This is in contrast to PEAT et al. [5] who concluded that dose response slope (calculated in the same way as DRR) contributed additional information to PD20, and discriminated more accurately between groups classified according to respiratory history.

It cannot solely be concluded which dose limit should be used from this cross-sectional study. It should be noted that among the control subjects who developed wheeze during the 1-2-yr observation period, $55 \%$ were hyperresponsive compared to $25 \%$ among those who continued to be asymptomatic. Thus a PD20 $\leq 2 \mathrm{mg}$ may be at least, if not confirmative of asthma, indicative of a higher risk for developing asthma symptoms over time.

ENO is another tool with which to measure suspected inflammation in the lower airways. There are several factors indicative of ENO reflecting airway inflammation. ENO is increased in asthma and a further increase is registered during asthma exacerbation [17] and viral infection [18]. Moreover, ENO has been found to be significantly associated with an increased number of eosinophils in induced sputum [19]. However, whether ENO is a general marker of inflammation, or merely reflects special types of inflammation, i.e. eosinophil driven inflammation as seen in atopic subjects, is still unclear. The authors found significantly higher levels of ENO among suspected asthmatics compared to the control subjects. Moreover, the highest values were found in those subjects, who were both hyperresponsive and had confirmed atopy, while the lowest values were found in nonatopic, nonhyperresponsive control subjects. The highest relative risk of having an elevated level of ENO was found in atopic versus nonatopic asthmatics. Moreover, the authors found a positive correlation between ENO level and degree of hyperresponsiveness. ENO, but not DRR, was significantly reduced in atopic asthmatics who were taking IGCS versus those who were not taking IGCS.

Interestingly, 10 subjects in the control group had AHR combined with ENO $\geq 8 \mathrm{ppb}$. Among these, five were atopic and three were either smokers or had signs of an ongoing cold. Whether these subjects are at a greater risk of developing asthma, so-called latent asthmatics, can only be answered by a follow-up investigation.

Suspected asthmatics with AHR (asthmatics) had higher ENO than control subjects with AHR. PIN et al. [20] studied children with and without respiratory symptoms and found higher eosinophil counts in induced sputum in symptomatic children with AHR compared to asymptomatic children with AHR. When considering the stronger correlation found between eosinophil counts in induced sputum and ENO compared to AHR [19], it can be speculated that ENO is more directly associated with the ongoing inflammation. Moreover, the reason why AHR was more frequent in suspected asthmatics compared to elevated ENO, may be that while ENO only reflects the short-term classic allergic reaction, AHR reflects both the short-term reaction and the continuous process of injury and healing remodelling.

In summary, measurements of AHR and ENO in a population survey add an additional dimension on the questionnaire data provided. The correct discriminating methacholine level for PD20 cannot be concluded from this study. While a PD20 $\leq 2 \mathrm{mg}$ gives a fair sensitivity, increasing the demand of AHR to a PD20 $\leq 0.5 \mathrm{mg}$ provides a higher specificity with acceptable sensitivity. There are, however, still a few control subjects with significant AHR. Whether these subjects really are control subjects or represent a specific risk group that later will develop asthma (latent asthmatics) is a task to be answered by follow-up studies. The incidence data in this study provided by the 0.5-2.5 yr follow-up of control subjects and suspected asthmatics indicate that this may be the case. 
Nitric oxide was found to provide additional information. The highest levels were found in atopic suspected asthmatics with confirmed airway hyperresponsiveness, whereas the lowest levels were found among nonhyperresponsive, nonatopic control subjects. The authors also found a significant correlation between the degree of airway hyperresponsiveness and levels of exhaled nitric oxide. In the control group 10 subjects still had both exhaled nitric oxide $\geq 8$ parts per billion and confirmed airway hyperresponsiveness. As with the control subjects with very low values of provocative dose of methacholine causing a $20 \%$ fall in forced expiratory volume in one second, the authors believe these subjects to be at a risk of developing asthma in the future, i.e. that they are latent asthmatics.

\begin{abstract}
Acknowledgements. The skilful technical assis-
\end{abstract} tance of T. Skaland is greatly appreciated.

\section{References}

1. Hoshino M, Nakamura Y, Sim JJ. Expression of growth factors and remodelling of the airway wall in bronchial asthma. Thorax 1998; 53: 21-27.

2. Crimi E, Spanevello A, Neri M, Ind PW, Rossi GA, Brusasco V. Dissociation between airway inflammation and airway hyperresponsiveness in allergic asthma. $\mathrm{Am} \mathrm{J}$ Respir Crit Care Med 1998; 157: 4-9.

3. Horvath I, Donnelly LE, Kiss A, et al. Combined use of exhaled hydrogen peroxide and nitric oxide in monitoring asthma. Am J Respir Crit Care Med 1998; 158: 10421046.

4. Nieminen MM, Lahdensuo A, Kellomaeki L, Karvonen J, Muittari A. Methacholine bronchial challenge using a dosimeter with controlled tidal breathing. Thorax 1988; 43: 896-900.

5. Peat JK, Salome CM, Berry G, Woolcock AJ. Relation of dose-response slope to respiratory symptoms and lung function in a population study of adults living in Busselton, Western Australia. Am Rev Respir Dis 1992; 146: 860-865.

6. Abramson MJ, Saunders NA, Hensley MJ. Analysis of bronchial reactivity in epidemiological studies. Thorax 1990; 45: 924-929.

7. Kharitonov SA, Yates D, Robbins RA, Logan-Sinclair R, Shinebourne EA, Barnes PJ. Increased nitric oxide in exhaled air of asthmatic patients. Lancet 1994; 15: 133-135.
8. Baraldi E, Azzolin NM, Zanconato S, Dario C, Zacchello F. Corticosteroids decrease exhaled nitric oxide in children with acute asthma. J Pediatr 1997; 131: 381-385.

9. Salome CM, Roberts AM, Brown NJ, Dermand J, Marks GB, Woolcock AJ. Exhaled nitric oxide measurements in a population sample of young adults. Am J Respir Crit Care Med 1999; 159: 911-916.

10. Asher MI, Keil U, Anderson HR, et al. International Study of Asthma and Allergies in Childhood (ISAAC): rationale and methods. Eur Respir J 1999; 8: 483-491.

11. Henriksen AH, Sue-Chu M, Lingaas Holmen T, Langhammer A, Bjermer L. Exhaled and nasal NO levels in allergic rhinitis: relation to sensitization, pollen season and bronchial hyperresponsiveness. Eur Respir J 1999; 13: 301-306.

12. Kharitonov S, Alving K, Barnes PJ. Exhaled and nasal nitric oxide measurements: recommendations. The European Respiratory Society Task Force. Eur Respir J 1997; 10: 1683-1693.

13. Zapletal A, Paul T, Samanek M. Normal values of static pulmonary volumes and ventilation in children and adolescents. Cesk Pediatr 1976; 31: 532-539.

14. Quanjer PH, Tammeling GJ, Cotes JE, Pedersen OF, Peslin R, Yernault JC. Lung volumes and forced ventilatory flows. Report Working Party Standardization of Lung Function Tests, European Community for Steel and Coal. Official Statement of the European Respiratory Society. Eur Respir J 1993; 6: Suppl 16, 5-40.

15. Shaheen SO, Sterne JA, Montgomery SM, Azima H. Birth weight, body mass index and asthma in young adults. Thorax 1999; 54: 396-402.

16. Kaplan TA, Montana E. Exercise-induced bronchospasm in nonasthmatic obese children. Clin Pediatr (Phila) 1993; 32: 220-225.

17. Kharitonov SA, O'Connor BJ, Evans DJ, Barnes PJ. Allergen-induced late asthmatic reactions are associated with elevation of exhaled nitric oxide. Am J Respir Crit Care Med 1995; 151: 1894-1899.

18. Kharitonov SA, Yates D, Barnes PJ. Increased nitric oxide in exhaled air of normal hurnan subjects with upper respiratory tract infections. Eur Respir J 1995; 8: 295297.

19. Jatakanon A, Lim S, Kharitonov SA, Chung KF, Barnes PJ. Correlation between exhaled nitric oxide, sputum eosinophils, and methacholine responsiveness in patients with mild asthma. Thorax 1998; 53: 91-95.

20. Pin I, Radford S, Kolendowicz R, et al. Airway inflammation in symptomatic and asymptomatic children with methacholine hyperresponsiveness. Eur Respir J 1993; 6: 1249-1256. 